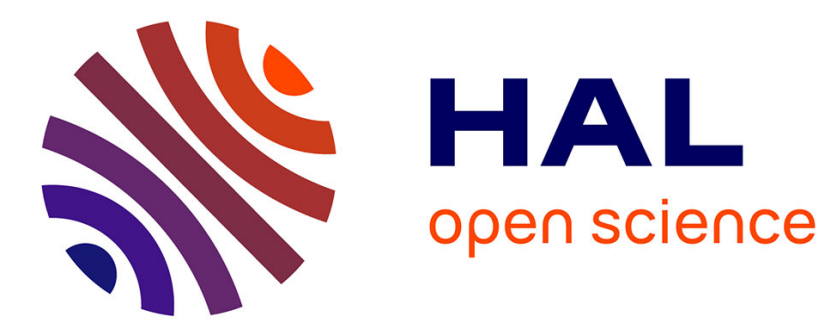

\title{
Dependence of titanium carbide stability at elevated temperatures on Co content in $\mathrm{Co}(\mathrm{Ni})-25 \mathrm{Cr}-1.6 \mathrm{Ti}-0.4 \mathrm{C}$ superalloys
}

Patrice Berthod, Lydia Toubal

\section{- To cite this version:}

Patrice Berthod, Lydia Toubal. Dependence of titanium carbide stability at elevated temperatures on Co content in $\mathrm{Co}(\mathrm{Ni})-25 \mathrm{Cr}-1.6 \mathrm{Ti}-0.4 \mathrm{C}$ superalloys. Materials Chemistry and Physics, 2018, 212, pp.260-267. 10.1016/j.matchemphys.2018.03.061 . hal-02902206

\section{HAL Id: hal-02902206 \\ https://hal.science/hal-02902206}

Submitted on 18 Jul 2020

HAL is a multi-disciplinary open access archive for the deposit and dissemination of scientific research documents, whether they are published or not. The documents may come from teaching and research institutions in France or abroad, or from public or private research centers.
L'archive ouverte pluridisciplinaire HAL, est destinée au dépôt et à la diffusion de documents scientifiques de niveau recherche, publiés ou non, émanant des établissements d'enseignement et de recherche français ou étrangers, des laboratoires publics ou privés. 


\title{
Dependence of titanium carbide stability at elevated temperatures on Co content in $\mathrm{Co}(\mathrm{Ni})-25 \mathrm{Cr}-1.6 \mathrm{Ti}-\mathrm{0.4C}$ superalloys
}

\author{
Patrice Berthod and Lydia Toubal
}

Institut Jean Lamour

Department $N^{\circ} 2$ : Chemistry and Physic of Solids and Surfaces Team "Surface and interface, chemical reactivity of materials" Faculty of Sciences and Technologies, University of Lorraine B.P. 70239, 54506 Vandoeuvre-lès-Nancy-France

Corresponding author's e-mail: pberthodcentralelille1987@ orange.fr

Corresponding author's phone: (33)3 83684666 and fax number: (33)3 83684611

Post-print version of the article Materials Chemistry and Physics 212 (2018) 260-267. https://doi.org/10.1016/j.matchemphys.2018.03.061

\begin{abstract}
Titanium carbides feature among the MC carbides which tend to crystallize with a script-like shape recognized to be favorable to mechanical strength at high temperature for equi-axed cast refractory alloys. Recent results demonstrated that script-like TiC can be successfully obtained in Co-based alloys while they are less stable than chromium carbides in nickel-based alloys. The present work aims to study whether the addition of cobalt to nickel-based alloys may stabilize TiC. This double investigation, by thermodynamic calculations and by the elaboration of a series of nickel-based alloys with an increasing part of cobalt, demonstrates that the progressive enrichment in cobalt tends favoring the presence of TiC instead chromium carbides. To obtain a majority of TiC, script-like shaped and in significant quantity, cobalt must be more present than nickel in the alloys. But this enrichment in cobalt deteriorates the good resistance against hot oxidation.
\end{abstract}

Keywords: alloys (A); solidification (B); electron microscopy (C); hardness (D); oxidation (D)

\section{Introduction}

The increase of needs in alloys offering high refractoriness, high temperature mechanical resistance, hot oxidation and corrosion resistance and possible manufacturability in complex shapes induces the maintenance of interest of the classical principle of equi-axed polycrystalline superalloys existing since several decades $[1,2]$. Some recent evolutions of chemical compositions allowing both high solidus temperature and good stability of the interdendritic strengthening particles such as MC 
carbides $[3,4]$. Beside the classical tantalum carbides or the maybe more innovative hafnium carbides, another $\mathrm{MC}$ carbide type, the $\mathrm{TiC}$ one, presents great potential interest thanks to the better availability of the involved metallic element. Titanium is a light metallic element, used for example for aeronautic components possibly exposed to moderate and even high temperatures (as aluminides $[1,2]$ ) or in in biomedical applications [5,6]. It is a strong carbide-former element, as well as a nitride-former one, this allowing it to be involved in bulk materials as well as in coatings, to improve the room or high temperature mechanical behaviour of various components [7-9]. In these applications titanium is often associated to other MC-former elements as $\mathrm{Nb}$ or $\mathrm{W}$, this leading to multimetallic MC carbides not necessarily very stable at high temperature [10-12].

In conventionally cast alloys, the presence of titanium together with carbon in equal atomic quantities allows obtaining, in some alloys, microstructures with interdendritic $\mathrm{TiC}$ as single carbide present, even in presence of high amount of another carbide-former element, chromium, added for combatting high temperature oxidation and corrosion $[13,14]$. This was observed, for example, in the case of $25 \mathrm{wt} . \% \mathrm{Cr}$ containing cobalt-based conventionally cast alloys [15].

But there are seemingly other cases for which $\mathrm{TiC}$ can be less stable than chromium carbides. For similar contents in all the other elements, titanium carbides are much less present than chromium carbides in as-cast nickel-chromium alloys, despite the atomic equivalence between $\mathrm{Ti}$ and $\mathrm{C}$ [16]. Furthermore, exposures to high temperature may lead to the total disappearance of the rare $\mathrm{TiC}$ initially present in the as-cast state.

Thus, in the family of the high temperature cast alloys based on cobalt or nickel, rich in chromium, containing titanium and carbon, and the strengthening principle of which is based on interdendritic carbides, one have:

- on the one hand the low chemically resistant but potentially strongly mechanically resistant TiC-reinforced cobalt-based alloys

- on the other hand the good chemically resistant but less efficiently resistant chromiumcarbides nickel-based alloys.

After having observed that TiC carbides successfully precipitate at solidification in cobalt-based alloys even in presence of large amount in chromium, with, in addition, a 
good stability during exposures at high temperature, and all the contrary for chromiumcontaining nickel-based alloys, one thought that some alloys containing simultaneously cobalt and nickel as base elements may present an intermediate microstructure behaviour, and why not a dense interdendritic TiC network in a nickel-based alloys thanks to the presence of a not too high amount in cobalt. Such possible result could lead to alloys presenting, at high temperature, both correct high temperature mechanical strength and good oxidation and corrosion resistance. This is what is investigated in the present work, by synthesizing a series of $\{25 \mathrm{Cr}, 0.4 \mathrm{C}$ and $1.6 \mathrm{Ti}$, wt. $\%\}$-containing alloys with varying $\mathrm{Co} / \mathrm{Ni}$ ratio, observing their as-cast microstructures and exploring their microstructural and surface stabilities during an isothermal exposure at a chosen high temperature and in an oxidative atmosphere.

\section{Material and methods}

\subsection{Selection the alloys}

For this study six chemical compositions of alloys were chosen. First, the chromium content was fixed at $25 \mathrm{wt} . \% \mathrm{Cr}$, which can be taken as a minimal value to hope remaining chromia-forming for nickel and cobalt-based alloys. Second the content in carbon was fixed at $0.4 \mathrm{wt} . \%$, which is known as being a value that allows obtaining an interdendritic carbide network (whatever the carbides' natures) dense enough to efficiently strengthen such alloys but not too developed to become interconnected and then to threaten the impact toughness/ crack propagation of the alloys. Third, the Co and $\mathrm{Ni}$ contents were chosen for targeting the $0,1,2,3,4$ and 5 values of the $\mathrm{Co} /(\mathrm{Ni}+\mathrm{Co})$ weight content ratio. The corresponding alloys are logically named "Ni5Co" (Ni-based), "Ni4Co1", "Ni3Co2", "Ni2Co3", "Ni1Co4" and "Ni0Co5" (Co-based). This repartition allows exploring uniformly the microstructure evolution gradually as the Co content increases.

\subsection{Thermodynamic calculations}

Predictive thermodynamic calculations were, prior to real experiments, carried out to anticipate the microstructures corresponding to theses chemical compositions. They were done using the Thermo-Calc software [17] and the SSOL database [18] enriched with additional thermodynamic data. The obtained database contains the 
description of many binary and ternary systems. Among them are the following Ticontaining ones: Ti-C, Ti-Ni, Ti-Co, Ti-Cr, Ti-Co-C and Ti-Cr-C.

\subsection{Elaboration}

The six alloys were synthesized by high frequency induction (about $100 \mathrm{kHz}$ ) melting. The charges of pure elements (Ni, Co, Cr, Ti: purity > 99.9\%, Alfa Aesar; C: pure graphite) were prepared to obtain 40 grams of alloy in case. Each charge was put in the copper crucible of a CELES furnace and a silica tube was placed around to isolate the fusion chamber from laboratory air. Pumping was applied until reaching about $7 \times$ $10^{-2}$ millibars, just before the injection of 800 millibars of pure argon. This cycle was thereafter applied two times again, before filling the chamber with pure argon for a final internal Ar pressure of about 200 millibars.

Heating was progressively performed, until $2.5 \mathrm{kV}$ in a first time. After apparent thermal homogenization of the parts of the pure elements, the voltage was increased again to reach $4 \mathrm{kV}$. After about 5 minutes of chemical homogenization in the liquid state, the applied power was progressively decreased. The alloys solidified (during about 1 minutes), then cooled in solid state. Their temperature reached the ambient one after about half an hour. The obtained ingots, compact-shaped, were thereafter cut in several parts for the characterization of their as-cast microstructures and for carrying out the exposures at high temperature.

\subsection{Exposure to high temperature and handling of the aged/oxidized samples}

After cutting with a metallographic saw (Abrasimet 5000 Delta Buehler), a quarter of each ingot was taken. These six parts were ground all around using 1200-grit $\mathrm{SiC}$ papers. They were placed in a Nabertherm muffle furnace, in which they were heated until reaching $1400 \mathrm{~K}$, temperature at which they were maintained during 20 hours before cooling. The aged samples were carefully handled to limit possible loss of the external oxide scale. A cathodic gold deposition was realized on their surface to get the outside electrical conductivity compulsory for the subsequent electrolytic nickel deposition. This later operation was carried out in a Watt's bath heated at $50^{\circ} \mathrm{C}$, with a operating parameters: $1.6 \mathrm{~A} / \mathrm{dm}^{2}$ and 2 hours. The samples, cathodically polarized 
(anodes: pure nickel coupons), were thus covered by a nickel coating thick enough to protect the external scales during the subsequent cutting leading to two halves allowing the preparation of samples for metallographic observation and indentation.

\subsection{Metallographic characterization}

For each alloy, the part kept for the as-cast microstructure observation and the one issued from aging, Au then Ni coatings and cross-sectional cutting, were embedded in a cold resin mixture. After total resin stiffening the samples were ground with successive SiC papers from \#250 to \#1200, ultrasonically cleaned, then finished using a textile disk enriched with $1 \mu \mathrm{m}$ hard particles. The obtained mirror-like state allowed metallographic observations by electron microscopy. This was done using a JEOL JSM6010LA scanning electron microscope (SEM), with an acceleration voltage equal to $20 \mathrm{kV}$. The Energy Dispersive Spectrometry attached to the SEM was used to control the general chemical composition of the alloys (full frame analysis at $\times 250$ ), to identify the different observed phases (alloy) and oxides (internal ones and external scale), by spot analysis at $\times 1000$ ), and to specify the chemical changes in the outer part of the aged alloys, notably by acquiring concentrations profiles.

\subsection{Comparison of the obtained microstructures in the aged states and the ones predicted by thermodynamic calculations}

Three $\times 1000$ images obtained in Back Scattered Electrons mode (BSE), randomly chosen, were analysed using the image analysis tool of Photoshop CS software of Adobe, to value the surface fractions of the different phases (notably carbides). By assuming that these surface values can be reasonably taken as very close to the real volume fractions, the later ones were converted in mass fractions, using the following values for the different densities: $9 \mathrm{~g} / \mathrm{cm}^{3}, 4.93 \mathrm{~g} / \mathrm{cm}^{3}$ and $6.95 \mathrm{~g} / \mathrm{cm}^{3}$ for the densities of the matrix, the $\mathrm{TiC}$ carbides and the $\mathrm{Cr}_{\mathrm{x}} \mathrm{C}_{\mathrm{y}}$ carbides, respectively. Thus, in addition to 
the carbides' natures and the matrix chemical compositions in the aged state, the obtained mass fractions were compared to the ones issued from Thermo-Calc.

\subsection{Hardness measurements}

The Vickers hardness of the six alloys in their as-cast states and in their aged states was specified with a Testwell Wolpert apparatus. Five indentations were carried out on each sample, under a 10kg load. These results led to an average value and a standard deviation value for each $\{$ alloy, state $\}$ couple.

\section{Results}

\subsection{Preliminary thermodynamic calculations}

Prior to the real elaboration of the alloys calculations were carried out with Thermo-Calc to explore the theoretic high temperature metallurgical states that can be expected with the selected composition. A isopleth section calculated for $\{25 \mathrm{wt} . \% \mathrm{Cr}$, $0.4 \mathrm{wt} . \% \mathrm{C}$ and $1.6 \mathrm{wt} . \% \mathrm{Ti}$, for varying cobalt content, is presented in Fig. 1, with the positions of the six alloys. One can see that, in all cases, solidification is expected to start with the crystallization of the austenitic FCC matrix. Solidification ought to continue with the appearance of $\mathrm{Cr}_{7} \mathrm{C}_{3}$ carbides (left side, poor in cobalt, Ni5Co0 and Ni4Co1 alloys) at almost constant temperature. For a cobalt content higher than about $1.5 \mathrm{wt} . \% \mathrm{Co}$ this is with the precipitation of $\mathrm{TiC}$ carbides together with matrix that solidification should go on, over several tens of Celsius degrees (case of the four other alloys, richer in $\mathrm{Co}$ ). For the two medium alloys, Ni3Co2 and $\mathrm{Ni2Co3}$, solidification ends with the appearance of a third solid phase, $\mathrm{Cr}_{7} \mathrm{C}_{3}$.

After subsequent solid state cooling, for temperatures higher than $900^{\circ} \mathrm{C}$, the high temperature microstructure of the nickel-based alloys with cobalt content lower than about $15 \mathrm{wt} . \%$ (case of the $\mathrm{Ni5Co} 0$ and $\mathrm{Ni4Co} 1$ alloys) ought to be single-phased, with as carbide phases, $\mathrm{Cr}_{7} \mathrm{C}_{3}$ only. On the cobalt-rich side, the frontier delimiting the left side of the $\{$ double-phased matrix $+\mathrm{TiC}\}$ domain being more tilted, the double-phased matrix $+\mathrm{TiC}$ metallurgical states may exist for cobalt contents greater than about $50 \mathrm{wt}$ \% Co close to $1300^{\circ} \mathrm{C}$, but $70 \mathrm{wt}$. $\%$ Co seems compulsory at temperatures close to $1100^{\circ} \mathrm{C}$ for maintaining this same double-phased state. If $\mathrm{Co}$ is less present a second carbide phase, a $\mathrm{M}_{7} \mathrm{C}_{3}$ chromium carbide one, may be present too. At $1400 \mathrm{~K}\left(1127^{\circ} \mathrm{C}\right)$, 
only the cobalt-based Ni0Co5 alloy can be expected as double-phased, with as carbide only $\mathrm{TiC}$, at this temperature. The three other alloys, Ni3Co2, Ni2Co3 and Ni1Co4 ought to be triple-phased at $1400 \mathrm{~K}$ : the face centered cubic matrix, $\mathrm{Cr}_{7} \mathrm{C}_{3}$ and $\mathrm{TiC}$.

\subsection{Chemical compositions and as-cast microstructures of the obtained alloys}

The obtained alloys, prepared as metallographic samples, were subjected to EDS measurements (three locations $\times 250$ ). Table 1 displays the average and standard deviation values calculated from these results. The $\mathrm{Ni}, \mathrm{Co}$ and $\mathrm{Ti}$ contents well fit the targeted values. The contents in $\mathrm{Cr}$ are a little higher than expected, but they remain close to what was wished. The as-cast microstructures of Ni5Co0, Ni4Co1, Ni3Co2, Ni2Co3 Ni1Co4 and Ni0Co5 are illustrated in the left part of Fig. 2, Fig. 3, Fig. 4, Fig. 5, Fig. 6 and Fig. 7 respectively, for two magnifications $(\times 250$ for general view and $\times 1000$ for detailed view). As this was anticipated by considering the thermodynamic calculation results presented above, the matrix is dendritic for all alloys, with presence of the carbides in the interdendritic spaces. Consistently with the thermodynamic calculations, only $\mathrm{Cr}_{7} \mathrm{C}_{3}$ are present in the Ni-based Ni5Co0 alloy (Fig. 2, left). Their acicular shape is typical of the eutectic $\mathrm{Cr}_{7} \mathrm{C}_{3}$ crystallizing during the solidification of chromium-rich carbon-containing nickel alloys. In addition to $\mathrm{Cr}_{7} \mathrm{C}_{3}$ (which have not the same acicular shape as previously) two other carbides are also present in the as-cast Ni4Co1 alloy (Fig. 3, left), few $\mathrm{Cr}_{23} \mathrm{C}_{6}$ and few TiC, besides the much more numerous $\mathrm{Cr}_{7} \mathrm{C}_{3}$. The first ones are issued to a limited solid state transformation of the high temperature $\mathrm{Cr}_{7} \mathrm{C}_{3}$ (predicted by Thermo-Calc for temperatures lower than $900^{\circ} \mathrm{C}$ ) while the second one was not expected (consequence of not really equilibrium solidification/chemical segregation). The two following alloys in the Co-increasing order (Ni3Co2 and Ni2Co3, Fig. 4 and Fig. 5, left, respectively) contain additionally some $\mathrm{Cr}_{23} \mathrm{C}_{6}$ carbides, with thus the three types of carbides represented. These $\mathrm{Cr}_{23} \mathrm{C}_{6}$ result from the more or less limited solid state transformation of the $\mathrm{Cr}_{7} \mathrm{C}_{3}$, started at higher temperature than for the former alloys, according to Thermo-Calc (Fig. 1). The two last alloys (Fig. 6 and Fig. 7, left), which were expected to solidify entirely with $\mathrm{TiC}$ as single carbides, are very rich in titanium carbides. Their greater fractions to appear during solidification allowed some of them growing with scriptlike shape demonstrating their eutectic origin. Indeed they are mixed with matrix while a part of 
TiC are much isolated. $\mathrm{Cr}_{23} \mathrm{C}_{6}$ carbides, paler than $\mathrm{TiC}$, are also present in the Ni1Co4 alloy: they appeared during the solid state cooling of the solidified alloy.

\subsection{Microstructures after exposure at $1400 \mathrm{~K}$ for 20 hours: qualitative} observations

Especial parts of the six alloys were exposed during $20 \mathrm{~h}$ at $1400 \mathrm{~K}$. The microstructures in this aged state are illustrated in the right side of Figs. 2-7. The initial acicular shape of the eutectic $\mathrm{Cr}_{7} \mathrm{C}_{3}$ having crystalized in the $\mathrm{Ni5Co} 0$ alloy has disappeared, the carbides $\left(\mathrm{Cr}_{7} \mathrm{C}_{3}\right.$ again) being now much rounder and compact. Additionally one can note the presence of secondary carbides having precipitated here and there. Similar results can be noted for the carbides in the Ni4Co1 and Ni3Co2 alloys. This also affected the chromium carbides of the Ni2Co3 and Ni1Co4 alloys. In contrast the TiC carbides obviously kept their initial script-like morphology. Concerning the cobalt-based alloy, Ni0Co5, the initial TiC carbides seem unaffected by the high temperature exposure, and no secondary carbides have appeared: its microstructure stays obviously unchanged during the exposure at $1400 \mathrm{~K}$.

\subsection{Microstructures after exposure at 1400K for 20 hours: quantitative study}

A more quantitative analysis of the effect of the aging has been done, first by comparing the measured chemical compositions of the matrix of the alloys. Results show (Table 2) that the chromium content of the matrix tended decreasing for the cobalt-poorest alloys and, in contrast, increasing for the cobalt-richest ones. In contrast, in the same time, the titanium contents in matrix tended increasing for the former and decreasing for the latter. This suggesting that these phenomena may result, for the cobalt-poorest alloys, from little increasing of the fraction of chromium carbides and little decreasing fraction of the titanium carbides, and of the inverse phenomena for the cobalt-richest alloys, it was attempted to specify the surface fractions of the two types of carbides $\left(\mathrm{Cr}_{7} \mathrm{C}_{3}\right.$ or $\mathrm{Cr}_{7} \mathrm{C}_{3}+\mathrm{Cr}_{23} \mathrm{C}_{6}$ on the one hand, and $\mathrm{TiC}$ on the second hand). The results are presented in Table 3 . It effectively appears that aging at $1400 \mathrm{~K}$ induced an increase in chromium carbides and a decrease in TiC for the four Co-poorest alloys and an increase in titanium carbides and a decrease in chromium carbides for the two Corichest alloys. 


\subsection{Consequence on the hardness of the alloys}

Since the quantity of carbides may influence the mechanical properties of the alloys at high temperature as well as their room temperature hardness and machinability, the total of surface fraction of all carbides counted together was calculated per alloy in its two states, compared, and studied in relation with their hardness at room temperature. The values of the cumulative carbide surface fraction of the alloys for their two states, as-cast and aged, are given in Table 4, as well as the indentation results (Vickers, $10 \mathrm{~kg}$ ).

One can see first that the total surface fraction of carbides tends decreasing with the Co content, whatever the metallurgical state of the alloys (as-cast or aged). Knowing the high hardness of the carbides, whatever their nature, by comparison with the metallic alloys, this suggests that a higher Co content tends to increase the hardness of the matrixes, a tendency not thwarted by the smoothing effect of the decrease in carbides. Second the aging induces a loss in hardness for all alloys. This loss in particularly high for the Co-poorest alloys (e.g. 50HV less for Ni5Co0 and Ni4Co1, 21 to $25 \mathrm{HV}$ less for the $\mathrm{Ni3Co} 2$ and $\mathrm{Ni} 2 \mathrm{Co} 3$ alloys, and $20 \mathrm{HV}$ less for the Ni1Co4 and Ni0Co5 alloys. It seems that the change in carbide morphology from acicular/script-like to compact/round, more important for the first alloys than for the last ones, is responsible of this smoothening which evocates a possible weakening of the high temperature mechanical properties.

\subsection{Comparison between the aged states and the thermodynamic calculations}

As shown in Table 2, in which the measured chemical compositions of the matrixes of the six alloys are compared to the ones calculated by Thermo-Calc, the values of contents in $\mathrm{Cr}$ and $\mathrm{Ti}$ are rather consistent, despite the small discripencies between the two sets of values. In both cases one can note the slow increase in $\mathrm{Cr}$ and the decrease in titanium in matrix when more and more cobalt is substituted to nickel in the alloys. Despite some more or less important discripencies between the mass fractions issued from the conversion of the measured surface fractions, and the ones directly issued from Thermo-Calc, one can see that experiment and calculations show the same evolutions of the chromium carbides fractions when the Co content increases (Table 5). This also true for the TiC fractions. One can remark in both cases (matrix 
composition and carbides fractions) that the agreement between the two is the best for the two extremities of the studied cobalt range (Ni5Co0 and Ni0Co5) and the worst for the intermediate alloys.

\subsection{Oxidation behavior}

After 20 hours at $1400 \mathrm{~K}$ in laboratory air all the samples were logically oxidized. Figure 8 illustrates their surface states. One can see that only a little oxide spallation took place, with as result only rare parts having lost their oxide over the whole initial thickness. This allowed characterizing thereafter the oxide scales in cross section, as well as internal oxidation and other subsurface modifications.

Figure 9 displays cross-sectional views of the oxidized surfaces. All alloys were seemingly covered all around by an external oxide scale. In the case of five Co-poorest alloys (Ni5Co0, Ni4Co1, Ni3Co2 Ni2Co3 and Ni1Co4) this one is made of chromia exclusively, with the additional presence of internal dioxides of titanium. One can also notice here and there, some parts of a thin scale of either $\mathrm{TiO}_{2}$ or $\mathrm{TiCr}_{2} \mathrm{O}_{4}$ covering the chromia scale. Obviously this outer part of the external scale has spalled off during cooling and only rare parts are still present. In the case of the last alloy, the cobalt-based Ni0Co5 one, catastrophic oxidation seemed starting here and there, characterized by the penetration of oxidation inside the alloy and with as results very locally thick oxides constituted by not only chromia (mainly at the alloy-scale interface) but also by the $\mathrm{CoCr}_{2} \mathrm{O}_{4}$ spinel in intermediate position and the $\mathrm{CoO}$ cobalt oxide outside. Figure 10, Figure 11 and Figure 12 show the concentration profiles obtained by successive spot EDS analyses. They illustrate the impoverishment in chromium, but also in titanium, of the studied alloys. Not only chromium, but also titanium diffuses towards the oxidation front, what explains the presence of their oxides close to chromia. One can also remark that the chromium content in extreme surface (at the interface separating the external oxide scale and the alloy) tends decreasing when the cobalt content increases in the alloy. With close to $10 \mathrm{wt} . \% \mathrm{Cr}$, acquired at a location not yet catastrophically oxidizing, and with some other locations with already local rapid and penetrating oxidation, it appeared obvious that the cobalt-richest alloy among the ones of this study are much more threatened by generalized catastrophic oxidation. 


\section{Discussion}

Titanium carbides involve a metallic element not so expensive as tantalum or hafnium and present additionally a lower density than the formers. Furthermore they possibly crystallize with the same script-like shape recognized as being favourable to high mechanic properties at elevated temperature (case of script-like $\mathrm{TaC}$ in cobaltbased alloys and of script-like HfC in cobalt-based and nickel-based alloys). One already knew that, in presence of high content in chromium (25wt.\% for example), the TiC carbides meet some serious difficulties to appear at solidification in nickel-based alloys and, thereafter, to stay stable during service at high temperature, while they are obtained without any problem in cobalt-based alloys, from where the interest to better know how the TiC stability evolves with an enrichment in $\mathrm{Ni}$ of a Co-based alloy, or with an enrichment in $\mathrm{Co}$ in a Ni-based alloy. The characterization of the series of alloys elaborated in this work brought responses that thermodynamic calculations did not bring with accuracy high enough despite the correct description this modelling tool allowed obtaining. Obviously, substituting more and more $\mathrm{Ni}$ by $\mathrm{Co}$ in a $\{\mathrm{Ni}-25 \mathrm{Cr}-0.4 \mathrm{C}-$ $1.6 \mathrm{Ti}$, wt.\% \} alloy allows the appearance at solidification of $\mathrm{TiC}$ thereafter stable enough at high temperature only if cobalt becomes in excess of nickel. Indeed, if this condition is respected about 1.8 vol.\% of $\mathrm{TiC}$ and more can be obtained at solidification and kept at $1400 \mathrm{~K}$, this certainly constituting a useful reinforcement of the alloys against mechanical stress and creep deformation. Chromium carbide may take part themselves to this strengthening but only during a short time which is not sufficiently long (become compact after only 20 hours at $1400 \mathrm{~K}$ ). Therefore it is preferable to obtain more TiC carbides, able to keep their script-like shape on long times, and for that it seems compulsory to remain very rich in cobalt in the alloy. However one saw that the Ni1Co4 alloy, finally based on cobalt and containing about $14.5 \mathrm{wt} . \%$ of $\mathrm{Ni}$, is both rather rich in script-like $\mathrm{TiC}$ carbides and resistant against high temperature oxidation. According to Fig. 1, it appears, in addition, almost as refractory as the Ni0Co5 alloy. But it is true that, on the only mechanical point of view it is clear that this is the Ni0Co5 alloy which appears as being the more stable and the strongest at high temperature.

A possibility to take benefit from the favourable morphology and the high stability at elevated temperature of the eutectic $\mathrm{TiC}$ and of the good resistance against hot oxidation of the Ni-enriched versions, is to depose $\mathrm{Ni}$ by pack-cementation in order to 
obtain an outer part of the alloys more resistant against high temperature oxidation (highest diffusion of $\mathrm{Cr}$, and, according to Thermo-Calc and Fig. 1, presence of chromium carbides acting as very available $\mathrm{Cr}$ reservoirs since located in the high diffusion paths which represent the interdendritic areas); Co-deposition of $\mathrm{Ni}$ and $\mathrm{Cr}$ maybe also envisaged to simultaneously enrich this outer part of alloy in chromium. This could contribute to favour the keeping of the chromia-forming behaviour over longer times too.

\section{Conclusion}

Founding, on TiC carbides, the strengthening of nickel-based alloys rich in chromiumsupposes a significant enrichment in cobalt leading more to a cobalt-based alloy than to a cobalt-enriched nickel-based alloy. 14.5 and even 30wt.\%Co appeared here clearly not sufficient. Having more cobalt than nickel effectively appeared as necessary to ensure obtaining of script-like TiC carbides stable at high temperature on long time. This benefit in high temperature mechanical behaviour is now to be verified and value. One can also predict that heat-treatment to obtain an intra-dendritic precipitation of dispersed fine carbides may be necessary for the metallurgical and mechanical optimisation of alloys issued from this $\mathrm{Ni}(\mathrm{Co})-25 \mathrm{Cr}-0.4 \mathrm{C}-1.6 \mathrm{Ti}$ base, or more precisely $\mathrm{Co}(\mathrm{Ni})-25 \mathrm{Cr}-0.4 \mathrm{C}-1.6 \mathrm{Ti}$. In addition, such alloys more based on cobalt than on nickel have the tendency to do not well behave in oxidation at high temperature. As for other more classical alloys, protective coatings can be applied to solve this problem, for example $\mathrm{Cr}$ enrichment done by pack-cementation.

\section{References}

[1] C.T. Sims, W.C. Hagel, The Superalloys, John Wiley \& Sons, New York, 1972.

[2] E. F. Bradley, Superalloys: A Technical Guide, ASM International, Metals Park, 1988.

[3] S. Michon, P. Berthod, L. Aranda, C. Rapin, R. Podor, P. Steinmetz, Application of thermodynamic calculations to study high temperature behavior of $\mathrm{TaC}$-strengthened Co-base superalloys, Calphad, 27(3) (2003) 289-294. 
[4] Patrice Berthod, Elodie Conrath, As-cast microstructures and behavior at high temperature of chromium-rich cobalt-based alloys strengthened by hafnium carbides, Materials Chemistry and Physics, 143 (2014) 1139-1148.

[5] J. H. C. Lin, S. J. Lo, C. P. Ju, Biocorrosion study of titanium-cobalt alloys, Journal of Oral Rehabilitation, 22(5) (1995) 331-335.

[6] A. E. Sytschev, S. G. Vadchenko, O. K. Kamynina, E. N. Balikhina, I. G. Plashchina, E. A. Krylova, A. S. Grigor'yan, A. K. Toporkova, A. N. Konovalov, I. I. Selezneva, Materials from titanium-cobalt alloys for hybrid implants, Bulletin of Experimental Biology and Medicine, 147(1) (2009) 160-165.

[7] S. Dodangeh, F. Shahri, S. M. Abbasi, The effects of carbon content on the microstructure and $650^{\circ} \mathrm{C}$ tensile properties of Incoloy 91 superalloy, High Temperature Materials and Processes, 34(8) (2015) 821-826.

[8] B. Zheng, T. Topping, J. E. Smugeresky, Y. Zhou, A. Biswas, D. Baker, E. J. Lavernia, The influence of Ni-coated TiC on laser-deposited IN625 metal matrix composites, 41A(3) (2010) 568-573.

[9] J. Zhou, F. Xie, J. Jia, N. Lin, X. Wu, Microstructure and dry sliding wear behavior of laser cladding ( $\mathrm{TiC}+\mathrm{TiN})-\mathrm{NiCrWC}$ powedr composite coating on DZ125 superalloy, Advanced Materials Research, 557-559 (2012) 1699-1703.

[10] W. Gui, H. Zhang, M. Yaang, T. Jin, X. Sun, Q. Zheng, The investigation of carbides evolution in a cobalt-base superalloy at elevated temperature, Journal of Alloys and Compounds, 695 (2017) 1271-1278.

[11] W. Sun, X. Z. Qin, W. Wang, T. T. Wang, Y. A. Guo, J. T. Guo, L. H. Lou, L. Z. Zhou, Effects of $\mathrm{Nb} / \mathrm{Ti}$ ratio on the microstructures of two experimental Ni-based cast superalloys, Materials Science Forum, 74748 (2013) 629-635.

[12] W. Sun, X. Qin, J. Guo, L. Lou, L. Zhou, Thermal stability of primary MC carbides and its influence on the performance of cast Ni-base superalloys, Materials and Design, 69 (2015) 81-88.

[13] P. Kofstad, High Temperature Corrosion, Elsevier applied science, London, 1988.

[14] D. Young, High Temperature Oxidation and Corrosion of Metals, Elsevier Corrosion Series, Amsterdam, 2008. 
[15] M. Khair, P. Berthod, As-cast microstructures and hardness of chromium-rich cobalt-based alloys reinforced by titanium carbides, Materials Science: An Indian Journal, 14(13) (2016) 102-109.

[16] P. Berthod, E. Kretz, F. Allègre, Experimental and thermodynamic study of the role of titanium in the microstructural and thermal properties of cast $\mathrm{Ni}-\mathrm{Cr}-\mathrm{C}-\mathrm{Ti}$ Alloys, Calphad, 56 (2017) 41-48.

[17] Thermo-Calc version N: "Foundation for Computational Thermodynamics"

Stockholm, Sweden, Copyright (1993, 2000). www.thermocalc.com

[18] SSOL database, SGTE Solutions Database, Scientific Group Thermodata Europe, Bo Sundman, Stockholm, Sweden. 
Table 1

General chemical compositions of the studied alloys (SEM/EDS at $\times 250$, average and standard deviation values from three measurements); weight $\%$

\begin{tabular}{|c|c|c|c|c|c|}
\hline Alloys & $\mathrm{Ni}$ & $\mathrm{Co}$ & $\mathrm{Cr}$ & $\mathrm{Ti}$ & C* \\
\hline Ni5Co0 & Bal. & 0.0 & $25.4 \pm 0.2$ & $1.6 \pm 0.1$ & “0.4" \\
\hline Ni4Co1 & Bal. & $14.5 \pm 0.1$ & $25.6 \pm 0.2$ & $1.6 \pm 0.1$ & “ $0.4 "$ \\
\hline Ni3Co2 & Bal. & $29.1 \pm 0.3$ & $25.3 \pm 0.2$ & $1.5 \pm 0.1$ & "0.4” \\
\hline Ni2Co3 & $29.4 \pm 0.1$ & Bal. & $25.3 \pm 0.3$ & $1.6 \pm 0.1$ & “0.4" \\
\hline Ni1Co4 & $14.8 \pm 0.1$ & Bal. & $25.6 \pm 0.3$ & $1.6 \pm 0.1$ & “0.4" \\
\hline Ni0Co5 & 0.0 & Bal. & $25.7 \pm 0.1$ & $1.6 \pm 0.1$ & " $0.4 "$ \\
\hline
\end{tabular}

*: not controlled (not possible by EDS), assumed to be respected

Table 2

Comparison between the $\mathrm{Cr}$ and $\mathrm{Ti}$ weight contents in the matrix of the alloys in their as-cast states and after aging at $1400 \mathrm{~K}$ for $20 \mathrm{~h}(\mathrm{SEM} / \mathrm{EDS}$ at $\times 250)$; comparison with the contents calculated with Thermo-Calc

\begin{tabular}{|c|c|c|c|c|c|c|}
\hline \multirow{2}{*}{ Alloys } & \multicolumn{3}{|c|}{ Chromium (wt.\%Cr) } & \multicolumn{3}{c|}{ Titanium (wt.\% Ti) } \\
\cline { 2 - 7 } & As-cast* & Aged* & $\begin{array}{c}\text { Thermo- } \\
\text { Calc }\end{array}$ & As-cast* & Aged* & $\begin{array}{c}\text { Thermo- } \\
\text { Calc }\end{array}$ \\
\hline Ni5Co0 & $24.1 \pm 0.4$ & $\mathbf{2 2 . 9} \pm \mathbf{0 . 1}$ & 22.32 & $1.3 \pm 0.2$ & $\mathbf{1 . 6} \pm \mathbf{0 . 1}$ & 1.67 \\
\hline Ni4Co1 & $24.1 \pm 0.6$ & $\mathbf{2 3 . 3} \pm \mathbf{0 . 1}$ & 22.40 & $1.0 \pm 0.3$ & $\mathbf{1 . 4} \pm \mathbf{0 . 1}$ & 1.67 \\
\hline Ni3Co2 & $24.3 \pm 0.2$ & $\mathbf{2 3 . 3} \pm \mathbf{0 . 4}$ & 24.07 & $0.9 \pm 0.1$ & $\mathbf{1 . 2} \pm \mathbf{0 . 1}$ & 0.81 \\
\hline Ni2Co3 & $24.3 \pm 0.2$ & $\mathbf{2 3 . 8} \pm \mathbf{0 . 7}$ & 24.83 & $0.8 \pm 0.1$ & $\mathbf{0 . 8} \pm \mathbf{0 . 1}$ & 0.44 \\
\hline Ni1Co4 & $24.6 \pm 0.3$ & $\mathbf{2 5 . 9} \pm \mathbf{0 . 2}$ & 25.32 & $0.8 \pm 0.1$ & $\mathbf{0 . 6} \pm \mathbf{0 . 1}$ & 0.30 \\
\hline Ni0Co5 & $24.5 \pm 0.3$ & $\mathbf{2 5 . 8} \pm \mathbf{0 . 2}$ & 25.39 & $0.6 \pm 0.1$ & $\mathbf{0 . 5} \pm \mathbf{0 . 2}$ & 0.27 \\
\hline
\end{tabular}

*SEM/EDS results: average and standard deviation values from three measurements

Table 3

Surface fractions of the two types of carbides between the two states (as-cast and aged for $20 \mathrm{~h}$ at $1127^{\circ} \mathrm{C}$ ) of the studied alloys (average and standard deviation values from three image analysis results, SEM/EDS at $\times 250$ )

\begin{tabular}{|c|c|c|c|c|}
\hline \multirow{2}{*}{ Alloys } & \multicolumn{2}{|c|}{$\mathrm{Cr}_{\mathrm{x}} \mathrm{C}_{\mathrm{y}}$ (surf.\%) } & \multicolumn{2}{c|}{ TiC (surf.\%) } \\
\cline { 2 - 5 } & As-cast & Aged & As-cast & Aged \\
\hline Ni5Co0 & $4.71 \pm l .91$ & $\mathbf{6 . 4 2} \pm \mathbf{0 . 0 6}$ & $0.19 \pm 0.07$ & $\mathbf{0 . 0 0}$ \\
\hline Ni4Co1 & $3.78 \pm 0.68$ & $\mathbf{5 . 7 1} \pm \mathbf{0 . 6 5}$ & $0.42 \pm 0.12$ & $\mathbf{0 . 2 5} \pm \mathbf{0 . 1 5}$ \\
\hline Ni3Co 2 & $3.34 \pm 0.27$ & $\mathbf{4 . 3 8} \pm \mathbf{0 . 5 6}$ & $0.53 \pm 0.01$ & $\mathbf{0 . 3 8} \pm \mathbf{0 . 1 6}$ \\
\hline Ni2Co 3 & $2.08 \pm l .31$ & $\mathbf{2 . 4 1} \pm \mathbf{0 . 1 7}$ & $1.89 \pm 0.04$ & $\mathbf{1 . 7 4} \pm \mathbf{0 . 4 5}$ \\
\hline Ni1Co 4 & $1.27 \pm 0.31$ & $\mathbf{2 . 4 9} \pm \mathbf{0 . 2 1}$ & $1.98 \pm 0.27$ & $\mathbf{2 . 1 9} \pm \mathbf{0 . 3 0}$ \\
\hline Ni0Co5 & $1.04 \pm 0.09$ & $\mathbf{0 . 0 0}$ & $2.03 \pm 0.24$ & $\mathbf{2 . 9 7} \pm \mathbf{0 . 2 5}$ \\
\hline
\end{tabular}


Table 4

Surface fractions of the two types of carbides together (left) calculated from Table 3, and Vickers hardness (right) for the two states (as-cast and aged for 20h at 1400K)

\begin{tabular}{|c|c|c|c|c|}
\hline \multirow{2}{*}{ Alloys } & \multicolumn{2}{|c|}{ All carbides (surf.\%) } & \multicolumn{2}{c|}{ Hardness $\left(\mathrm{HV}_{10 \mathrm{~kg}}\right.$ ) } \\
\cline { 2 - 5 } & As-cast & Aged & As-cast & Aged \\
\hline Ni5Co0 & 4.9 & $\mathbf{6 . 4}$ & $189 \pm 8$ & $\mathbf{1 3 9} \pm \mathbf{1 8}$ \\
\hline Ni4Co1 & 4.2 & $\mathbf{6 . 0}$ & $204 \pm 5$ & $\mathbf{1 5 3} \pm \mathbf{1 6}$ \\
\hline Ni3Co2 & 3.9 & $\mathbf{4 . 8}$ & $187 \pm 17$ & $\mathbf{1 6 6} \pm \mathbf{1 2}$ \\
\hline Ni2Co3 & 4.0 & $\mathbf{4 . 2}$ & $185 \pm 7$ & $\mathbf{1 6 0} \pm \mathbf{1 3}$ \\
\hline Ni1Co4 & 3.3 & $\mathbf{4 . 7}$ & $239 \pm 18$ & $\mathbf{2 1 8} \pm \mathbf{3 2}$ \\
\hline Ni0Co5 & 3.1 & $\mathbf{3 . 0}$ & $264 \pm 23$ & $\mathbf{2 4 4} \pm \mathbf{2 3}$ \\
\hline
\end{tabular}

Table 5

Comparison of the mass fractions* of the chromium carbides and of the TiC carbides present in the $\{20 \mathrm{~h}, 1400 \mathrm{~K}\}$-aged alloys and the corresponding values calculated by Thermo-Calc

\begin{tabular}{|c|c|c|c|c|}
\hline \multirow{2}{*}{ Alloys } & \multicolumn{2}{|c|}{$\begin{array}{c}\text { Mass fraction of } \mathrm{Cr}_{\mathrm{x}} \mathrm{C}_{\mathrm{y}} \\
\text { (mass. } \% \text { ) }\end{array}$} & \multicolumn{2}{c|}{ Mass fraction of TiC (mass.\%) } \\
\cline { 2 - 5 } & $\begin{array}{c}\text { Aged 20h at } \\
\mathbf{1 4 0 0 K}\end{array}$ & $\begin{array}{c}\text { Thermo-Calc } \\
1400 \mathrm{~K}\end{array}$ & $\begin{array}{c}\text { Aged 20h at } \\
\mathbf{1 4 0 0 K}\end{array}$ & $\begin{array}{c}\text { Thermo-Calc } \\
1400 \mathrm{~K}\end{array}$ \\
\hline Ni5Co0 & $\mathbf{3 . 5 7}$ & $4.03\left(\mathrm{M}_{7} \mathrm{C}_{3}\right)$ & $\mathbf{0}$ & 0 \\
\hline Ni4Co1 & $\mathbf{3 . 1 7}$ & $4.02\left(\mathrm{M}_{7} \mathrm{C}_{3}\right)$ & $\mathbf{0 . 1 4}$ & 0 \\
\hline Ni3Co2 & $\mathbf{2 . 4 3}$ & $1.86\left(\mathrm{M}_{7} \mathrm{C}_{3}\right)$ & $\mathbf{0 . 2 1}$ & 1.03 \\
\hline Ni2Co3 & $\mathbf{1 . 3 3}$ & $0.82\left(\mathrm{M}_{7} \mathrm{C}_{3}\right)$ & $\mathbf{0 . 9 7}$ & 1.48 \\
\hline Ni1Co4 & $\mathbf{1 . 3 8}$ & $0.26\left(\mathrm{M}_{7} \mathrm{C}_{3}\right)$ & $\mathbf{1 . 2 2}$ & 1.66 \\
\hline Ni0Co5 & $\mathbf{0}$ & 0 & $\mathbf{1 . 6 5}$ & 1.70 \\
\hline
\end{tabular}

*: issued from volume fractions, assumed to be close to the surface fractions using $9 \mathrm{~g} / \mathrm{cm}^{3}, 4.93 \mathrm{~g} / \mathrm{cm}^{3}$ and $6.95 \mathrm{~g} / \mathrm{cm}^{3}$ for the densities of the matrix, the TiC carbides and the $\mathrm{Cr}_{\mathrm{x}} \mathrm{C}_{\mathrm{y}}$ carbides, respectively 


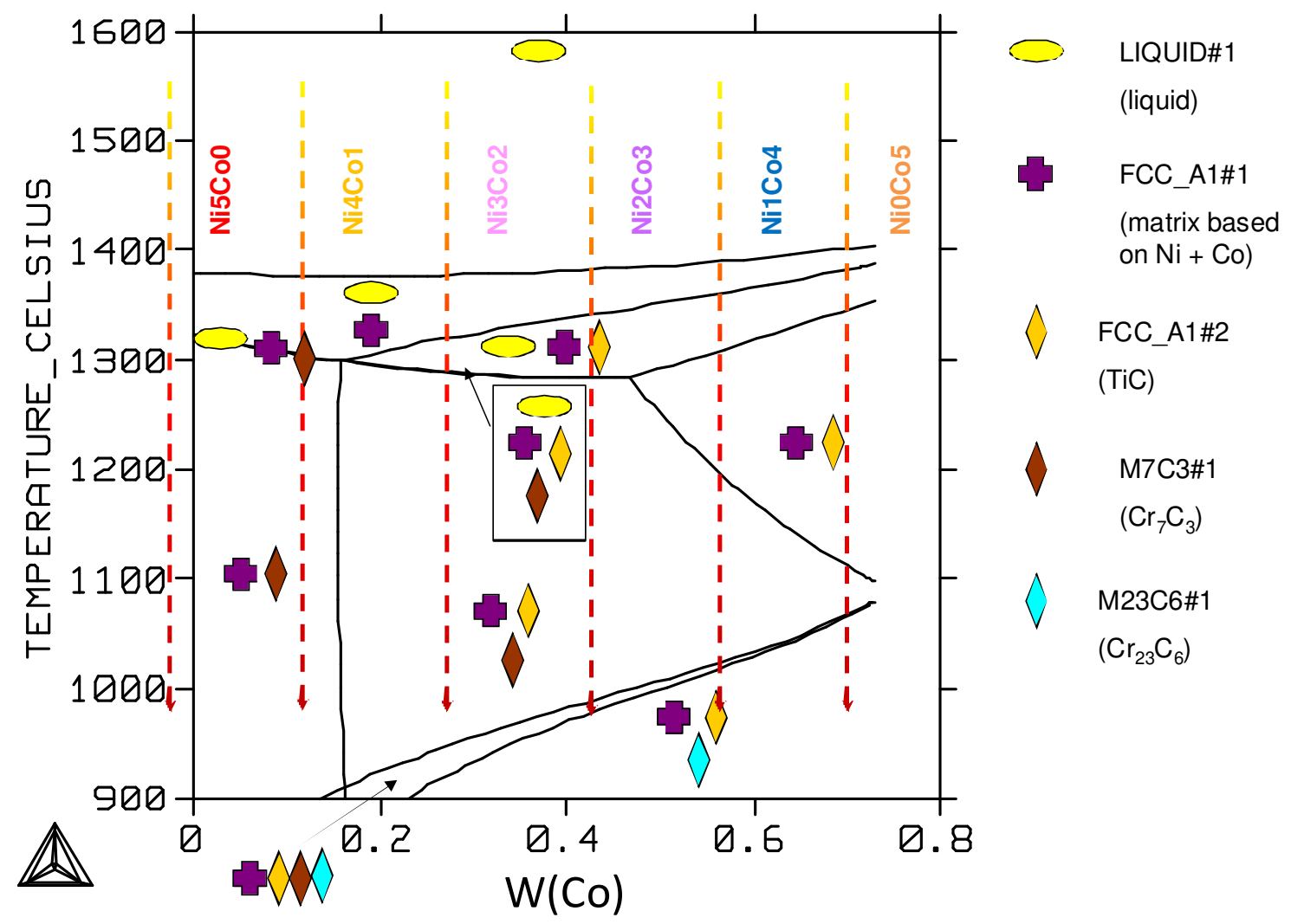

Fig. 1. Isopleth section computed with Thermo-Calc for $25 \mathrm{wt} . \% \mathrm{Cr}, 1.6$ wt. $\% \mathrm{Ti}$ and $0.4 \mathrm{wt} . \% \mathrm{C}$ 


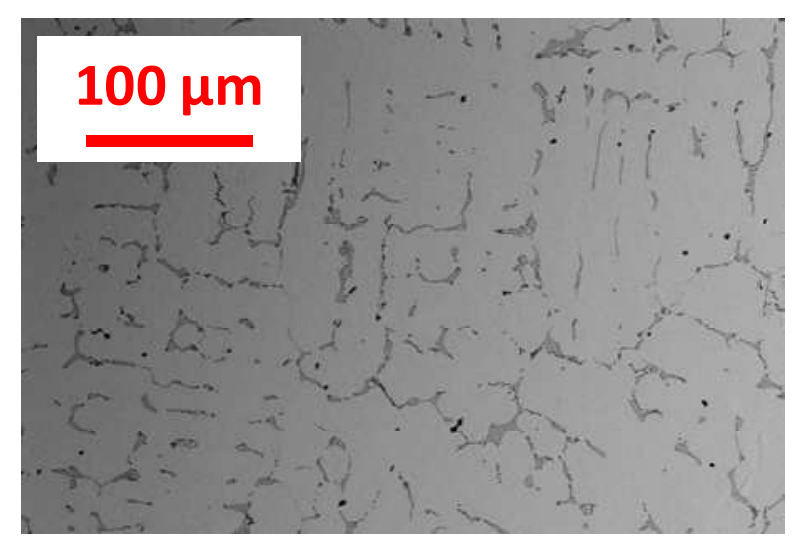

as-cast

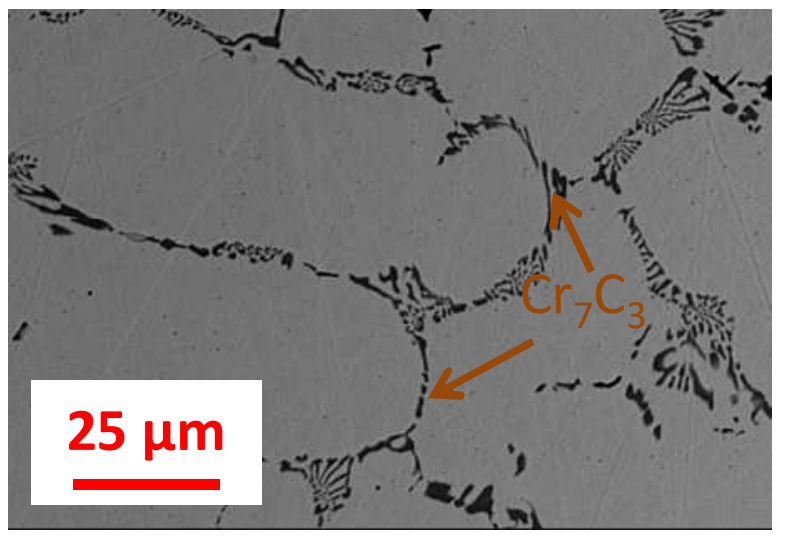

\section{Ni5Co0 alloy}

aged $20 \mathrm{~h}$ at $1400 \mathrm{~K}$

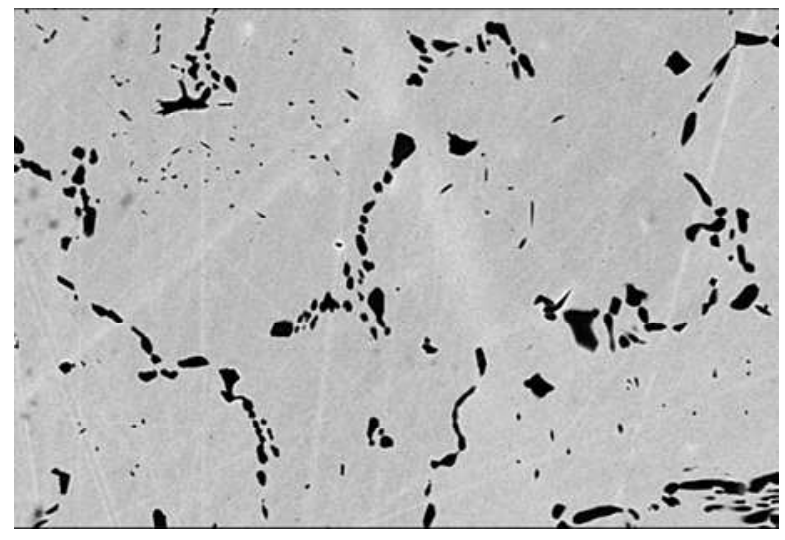

Fig. 2. General (left, top) and detailed (left, bottom) view of the as-cast microstructure of the $\mathrm{Ni} 5 \mathrm{Co} 0$ alloy; detailed view of the microstructure after $\{20 \mathrm{~h}, 1400 \mathrm{~K}\}$-aging (right); all micrographs taken with the SEM in BSE mode 


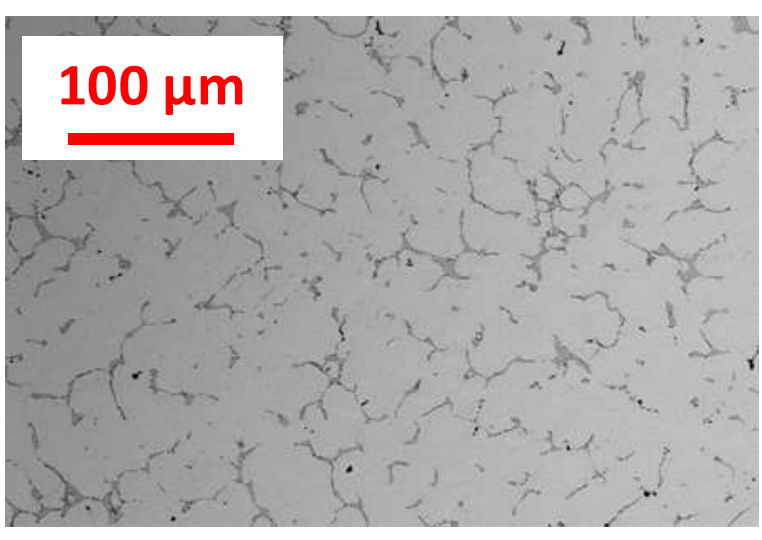

as-cast

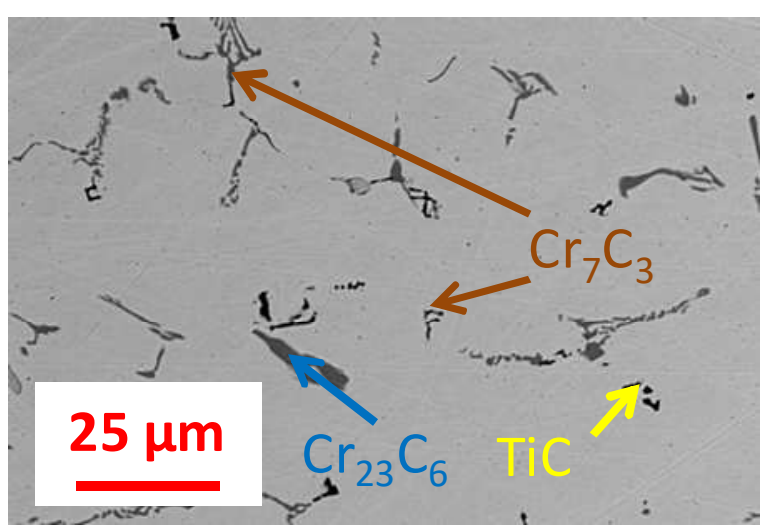

\section{Ni4Co1 alloy}

aged $20 \mathrm{~h}$ at $1400 \mathrm{~K}$

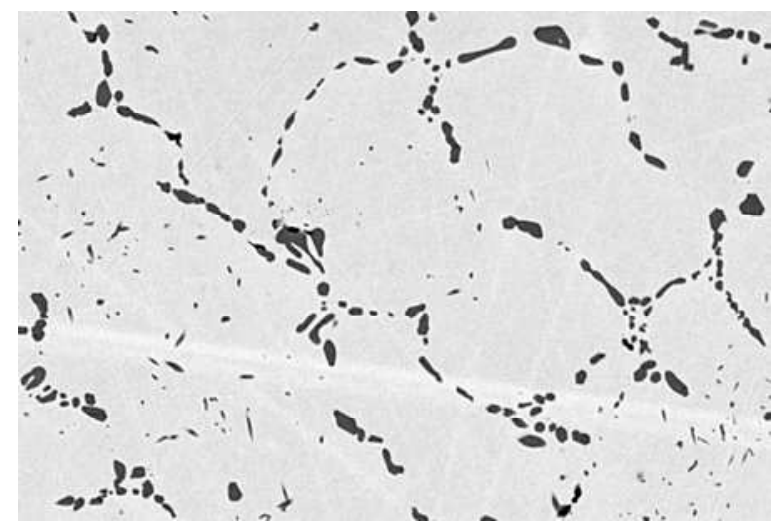

Fig. 3. General (left, top) and detailed (left, bottom) view of the as-cast microstructure of the Ni4Co1 alloy; detailed view of the microstructure after $\{20 \mathrm{~h}, 1400 \mathrm{~K}\}$-aging (right); all micrographs taken with the SEM in BSE mode 


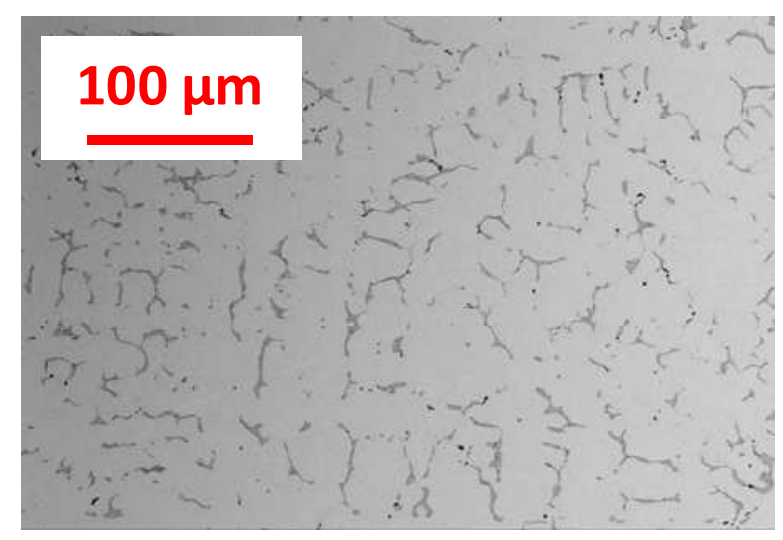

as-cast

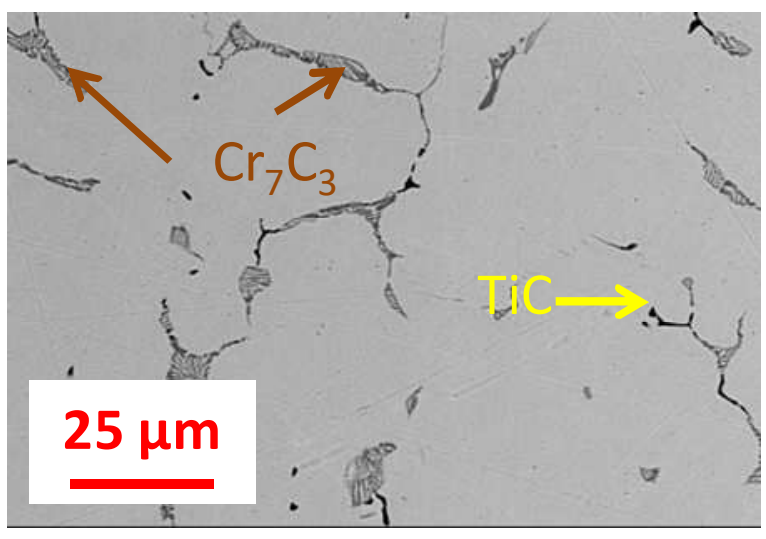

\section{Ni3Co2 alloy}

aged $20 \mathrm{~h}$ at $1400 \mathrm{~K}$

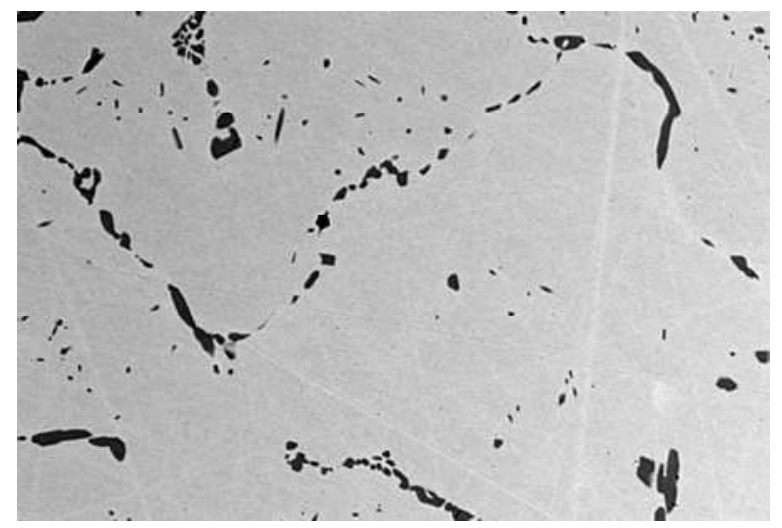

Fig. 4. General (left, top) and detailed (left, bottom) view of the as-cast microstructure of the Ni3Co2 alloy; detailed view of the microstructure after $\{20 \mathrm{~h}, 1400 \mathrm{~K}\}$-aging (right); all micrographs taken with the SEM in BSE mode 


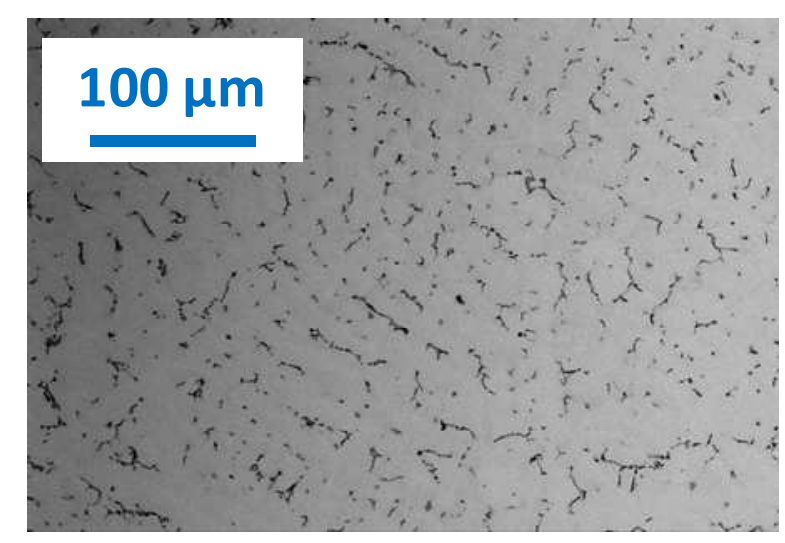

as-cast

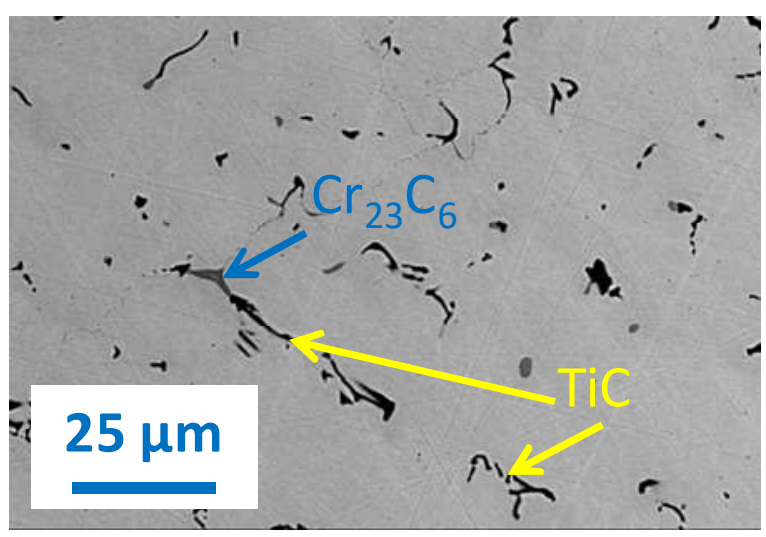

\section{Ni2Co3 alloy}

\section{aged $20 \mathrm{~h}$ at $1400 \mathrm{~K}$}

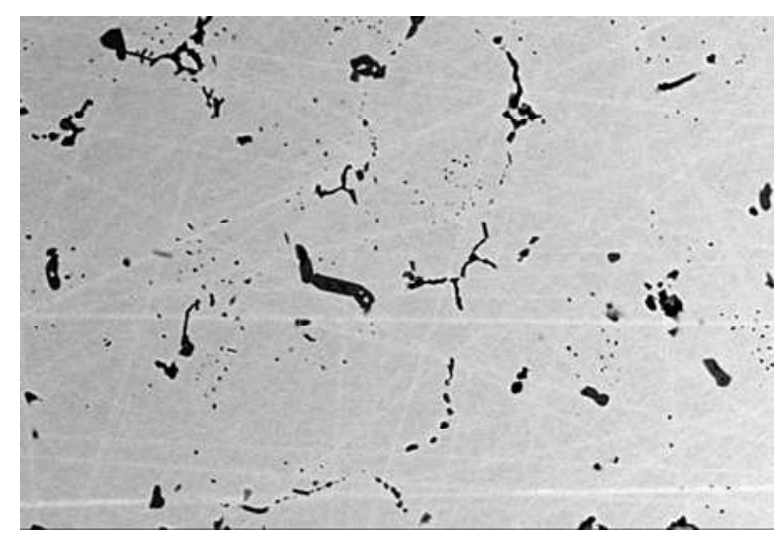

Fig. 5. General (left, top) and detailed (left, bottom) view of the as-cast microstructure of the Ni2Co3 alloy; detailed view of the microstructure after $\{20 \mathrm{~h}, 1400 \mathrm{~K}\}$-aging (right); all micrographs taken with the SEM in BSE mode 


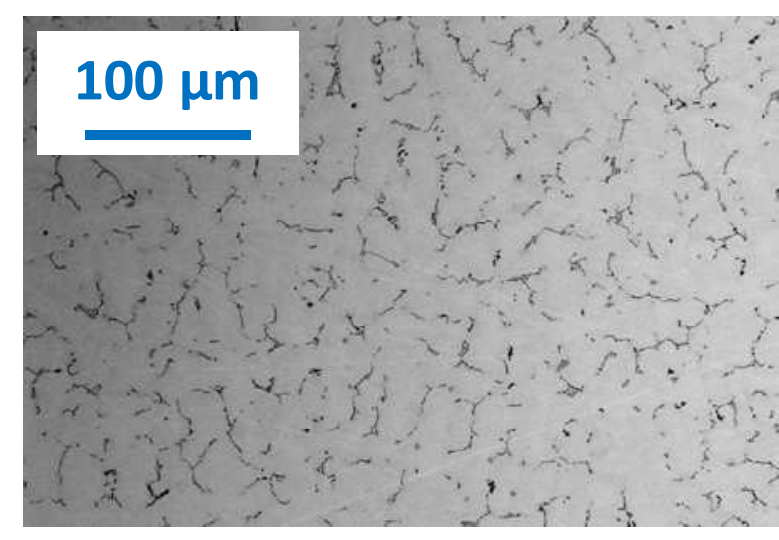

as-cast

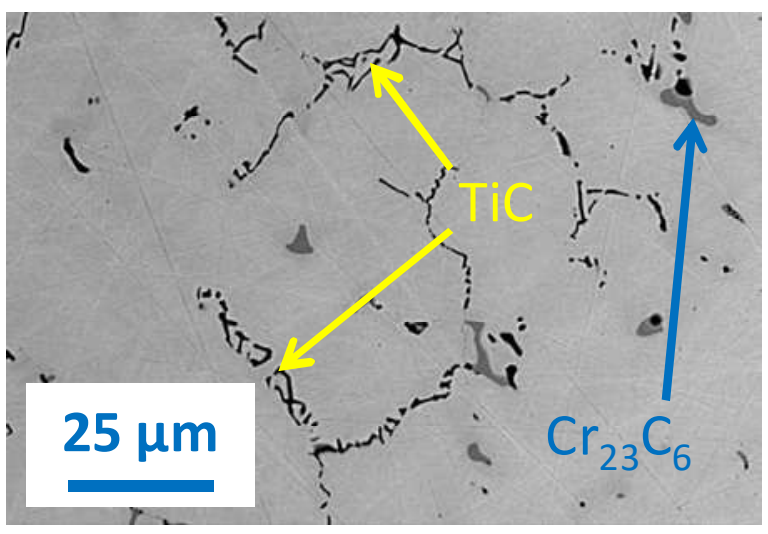

\section{Ni1Co4 alloy}

aged $20 \mathrm{~h}$ at $1400 \mathrm{~K}$

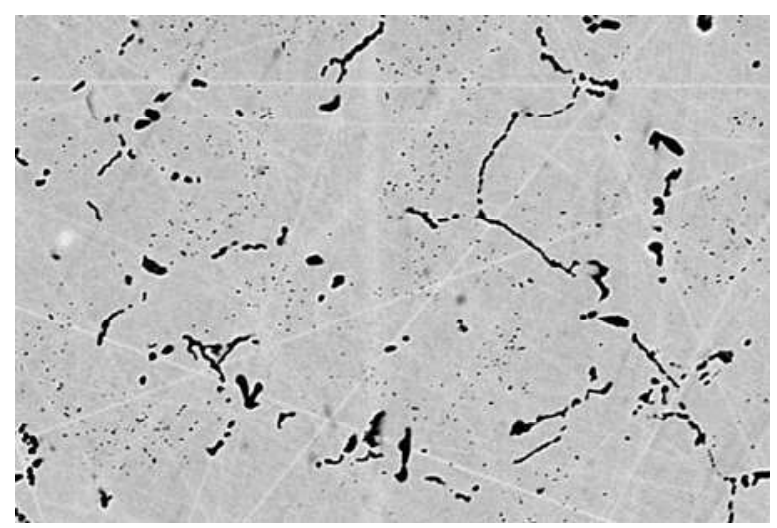

Fig. 6. General (left, top) and detailed (left, bottom) view of the as-cast microstructure of the Ni1Co4 alloy; detailed view of the microstructure after $\{20 \mathrm{~h}, 1400 \mathrm{~K}\}$-aging (right); all micrographs taken with the SEM in BSE mode 


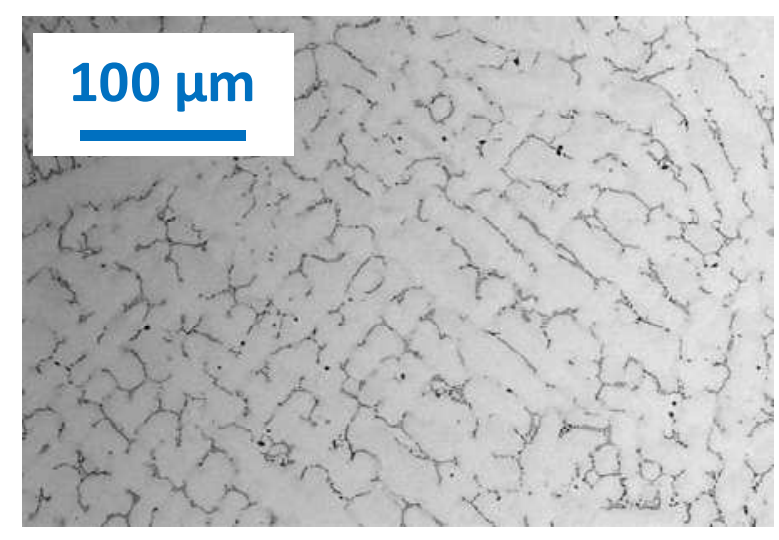

as-cast

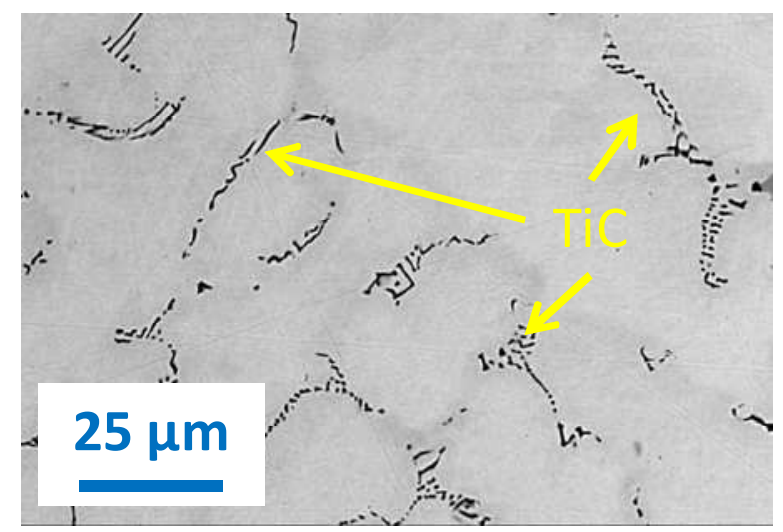

\section{Ni0Co5 alloy}

aged $20 \mathrm{~h}$ at $1400 \mathrm{~K}$

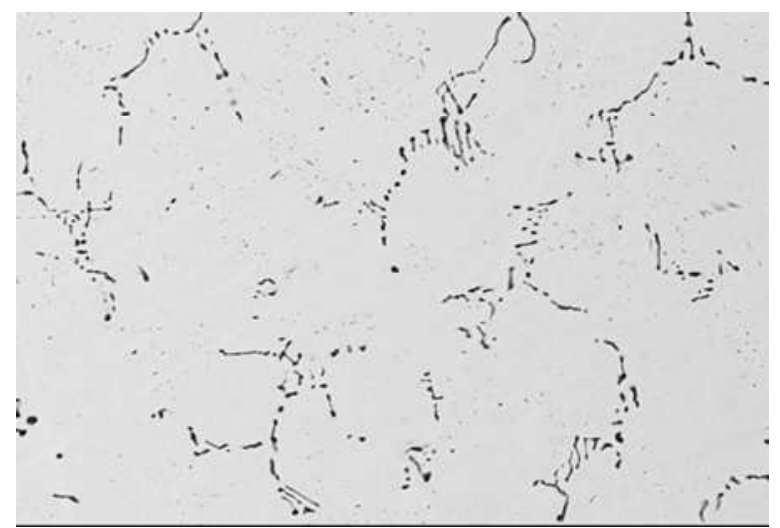

Fig. 7. General (left, top) and detailed (left, bottom) view of the as-cast microstructure of the Ni0Co5 alloy; detailed view of the microstructure after $\{20 \mathrm{~h}, 1400 \mathrm{~K}\}$-aging (right); all micrographs taken with the SEM in BSE mode 

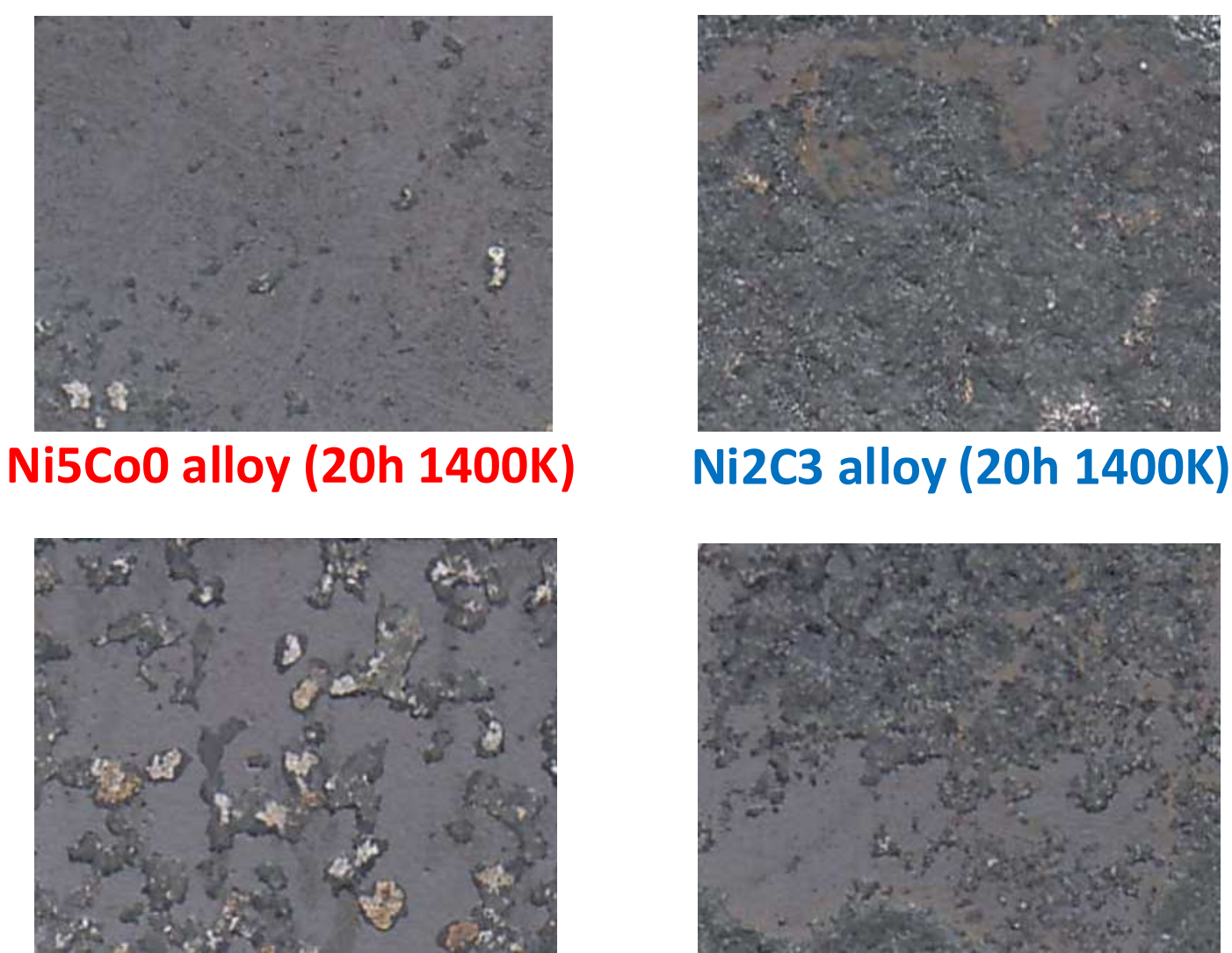

Ni2C3 alloy (20h 1400K)

Ni4Co1 alloy (20h 1400K)

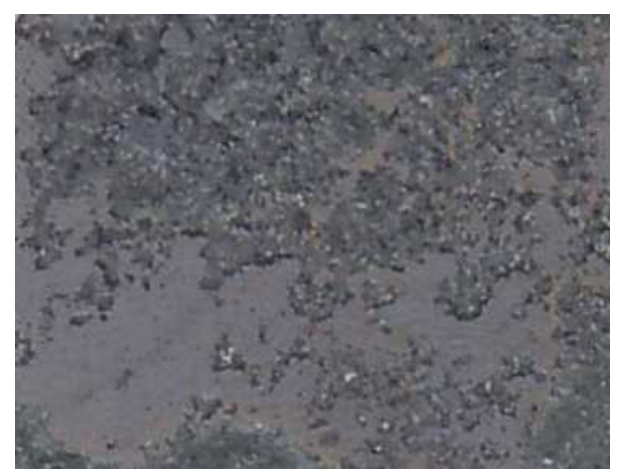

Ni1Co4 alloy (20h 1400K)
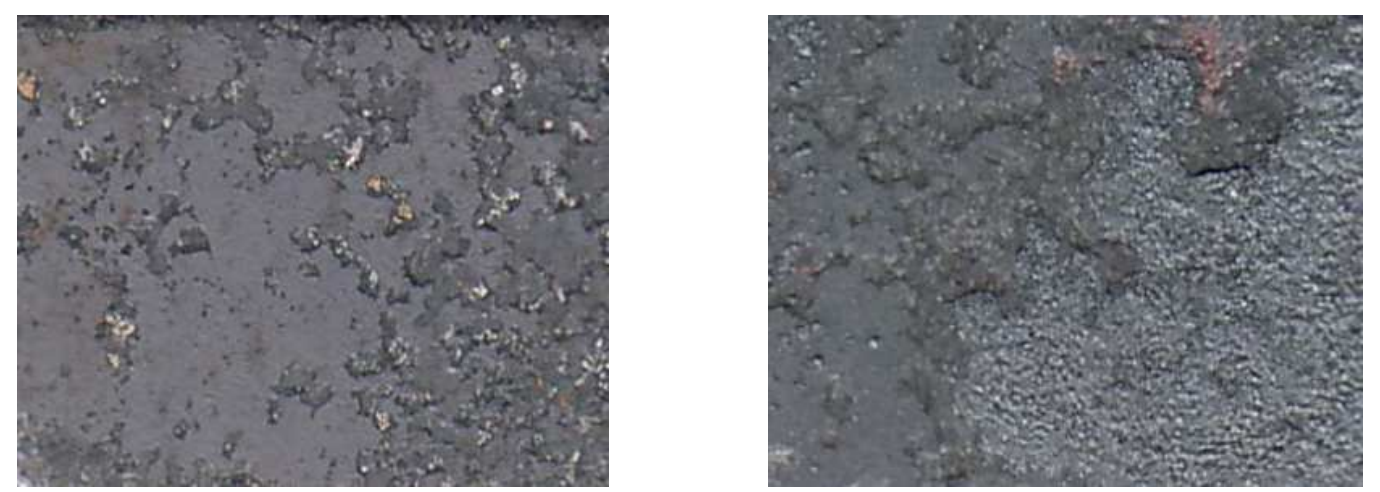

Ni3Co2 alloy (20h 1400K)

Ni0Co5 alloy (20h 1400K) $10 \mathrm{~mm}$

Fig. 8. Oxidized states of the six alloys after $20 \mathrm{~h}$ of aging at $1400 \mathrm{~K}$ in atmospheric air 


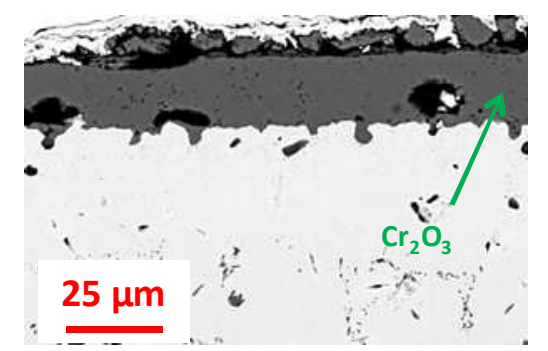

Ni5Co0 alloy (20h 1400K)

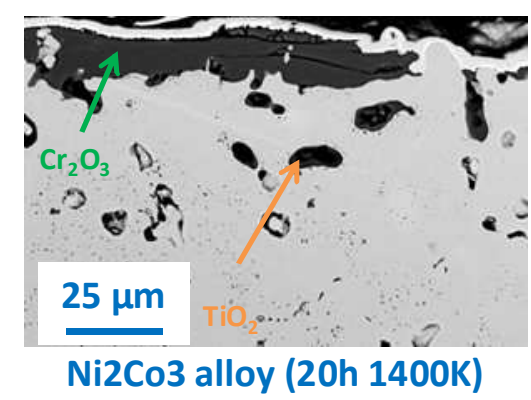

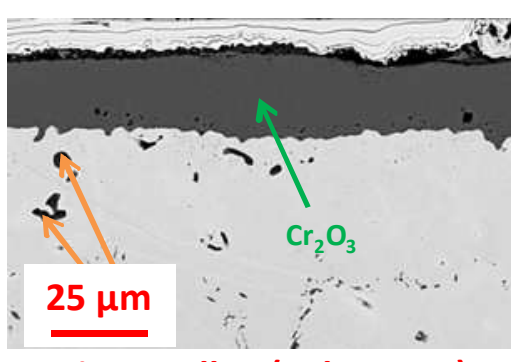

Ni4Co1 alloy (20h 1400K)

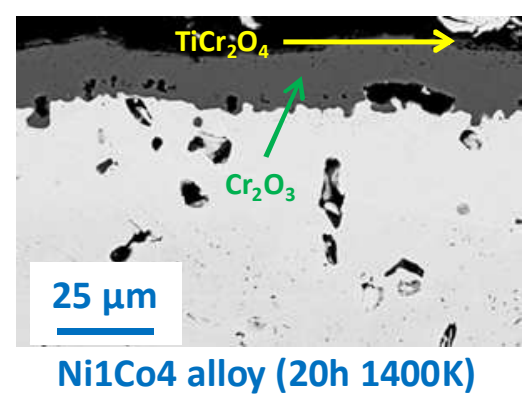

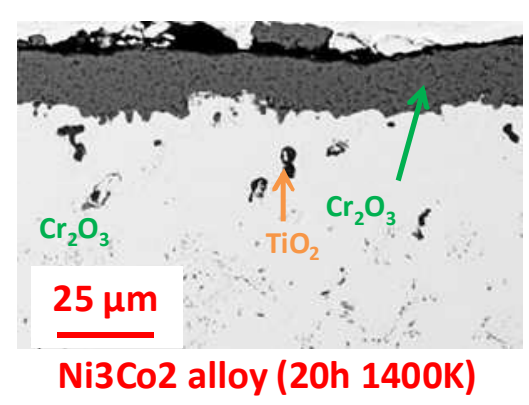

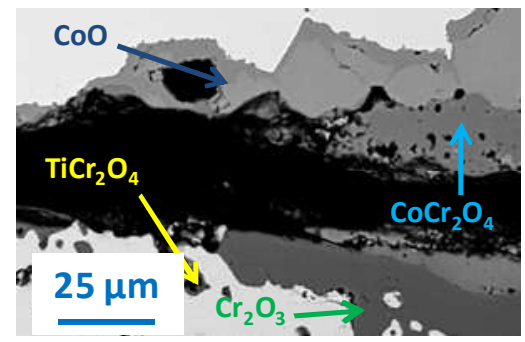

NiOCo5 alloy (20h 1400K)

Fig. 9. Cross-sectional detailed view of the surface and subsurface alloys oxidized for $20 \mathrm{~h}$ at $1400 \mathrm{~K}$ in atmospheric air; identification of the oxides in the external scales and of the internal oxides

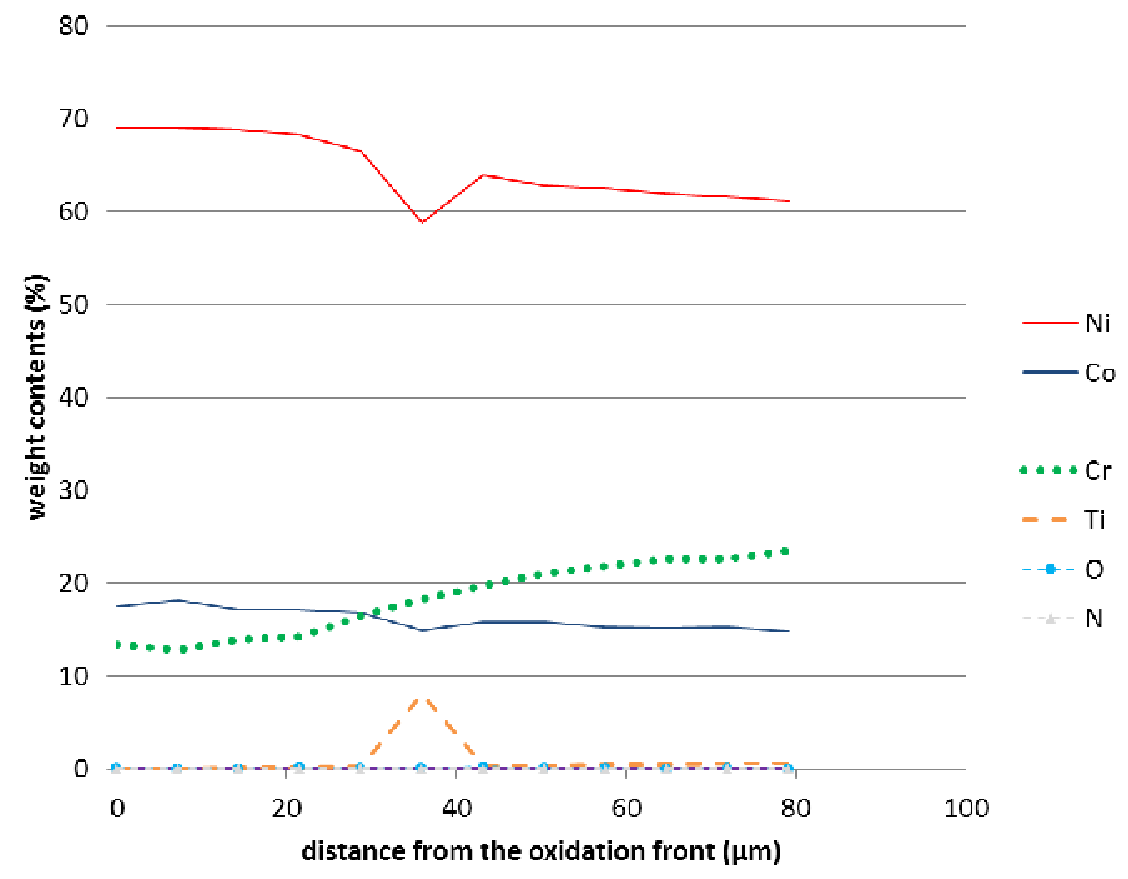

Ni4Co1 alloy (20h 1400K)

Fig. 10. Concentration profile from the oxidation front for alloy Ni4Co1 after oxidation at $1400 \mathrm{~K}$ for $20 \mathrm{~h}$ 


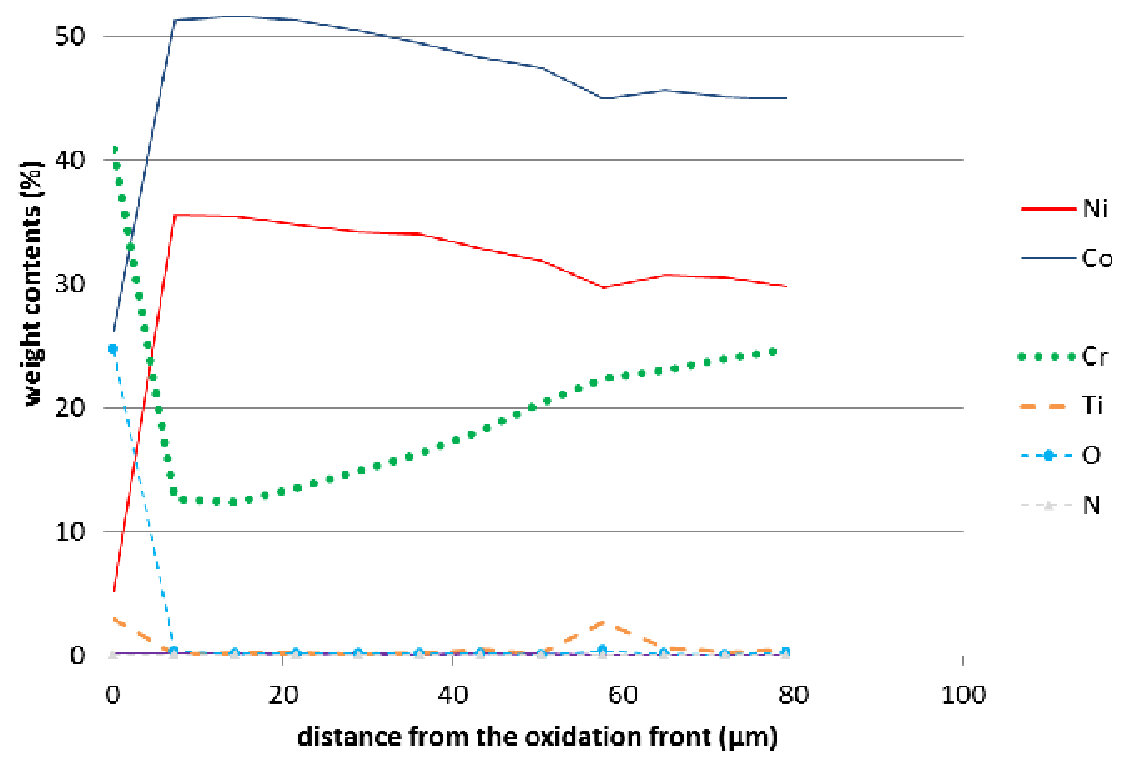

Ni2Co3 alloy (20h 1400K)

Fig. 11. Concentration profile from the oxidation front for alloy Ni2Co3 after oxidation at $1400 \mathrm{~K}$ for $20 \mathrm{~h}$

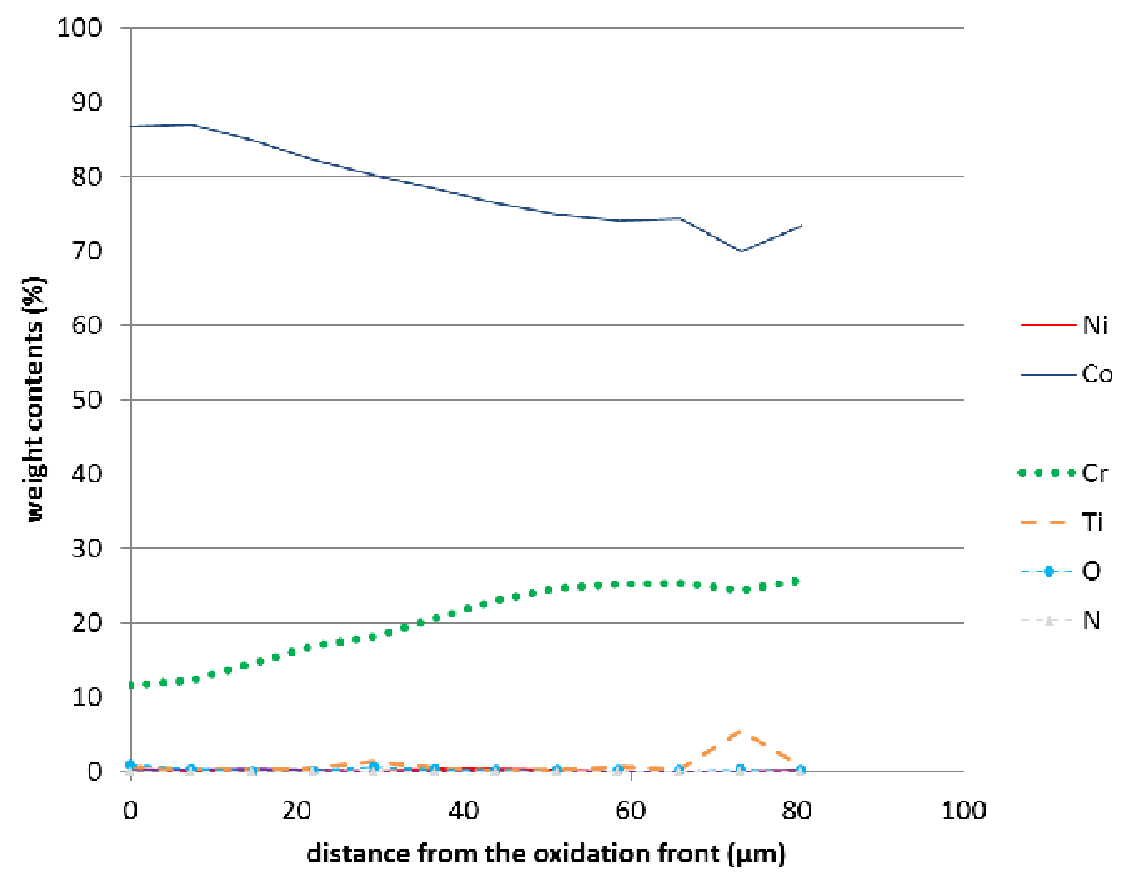

NiOCo5 alloy (20h 1400K)

Fig. 12 Concentration profile from the oxidation front for alloy Ni0Co5 after oxidation at $1400 \mathrm{~K}$ for $20 \mathrm{~h}$ 